Running head: PERITRAUMATIC REACTIONS, GENDER DIFFERENCES, PTSD

\title{
Prediction of Posttraumatic Stress Disorder from Peritraumatic Dissociation and Distress among Men and Women Victims of Violent Crimes
}

\author{
Julie Boisclair Demarble, Christophe Fortin, Bianca D'Antono and Stéphane Guay \\ Université de Montréal, Montréal, Quebec, Canada
}

\begin{abstract}
Author note
Julie Boisclair Demarble, Department of Psychology, Université de Montréal; Christophe Fortin, School of Criminology, Université de Montreal, and'Trauma Studies Center, Institut Universitaire en Santé Mentale de Montréal, Montreal, Quebec, Canada; Bianca D'Antono, Department of Psychology, Université de Montréal, and Research Center, Montreal Heart Institute, Montreal, Quebec, Canada; Stéphane Guay, School of Criminology, Université de Montreal and Trauma Studies Center, Institut Universitaire en Santé Mentale de Montréal.

This research was supported by grants awarded to Dr Guay by the Canadian Institutes of Health and Research (CIHR). Julie Boisclair Demarble was supported by a Masters' scholarship from the Fonds de la recherche en santé du Québec (FRSQ) and by various bursaries awarded from the department of psychology. We would also like to thank the Quebec's Crime Victim's Assistance Centers of Montreal and the Institut Universitaire en Santé Mentale de Montréal for their generous support of this study.
\end{abstract}

Correspondence concerning this article should be addressed to Stéphane Guay, Trauma Studies Center, Institut Universitaire en Santé Mentale de Montréal

Email: stephane.guay@umontreal.ca 


\begin{abstract}
Objective. Contradictory evidence exists regarding the role of peritraumatic distress (PDI) and dissociation (PD) in the development of PTSD. Victims of certain trauma types may be more susceptible to these peritraumatic reactions. Few studies have assessed gender differences in these associations, particularly among victims of violent crimes. This prospective study evaluated the main and interactive effects of peritraumatic reactions with gender on PTSD onset, independently of known risk factors. Methods. 111 adult victims of violent crime (68 women, $\left.\mathrm{M}_{\mathrm{age}}=41.23\right)$ completed the Structured Clinical Interview, the Modified PTSD symptom Scale, the Peritraumatic Dissociative Experience Questionnaire, and the Peritraumatic Distress Inventory. Hierarchical regressions and chi-square tests were conducted for continuous and categorical measures of PTSD. Results. Extremely elevated scores of PD and PDI were obtained for both sexes. Greater PDI and PD were related to more PTSD symptoms $(b=0.380, p=.001 ; b$ $=0.217, \mathrm{p}=.025$, respectively). No significant interaction effects with gender emerged. These results remained when acute stress disorder was controlled for. Analyses on categorical data produced similar results. Conclusion. Victims of violent crimes recall severe peritraumatic reactions. The more severe these are, the more likely they are to develop significant PTSD symptomatology in the months that follow.
\end{abstract}

Keywords: victims, violent crimes, post traumatic stress disorder, peritraumatic dissociation, peritraumatic distress, gender 


\section{Introduction}

Surviving a violent crime such as a physical or sexual assault is one of the traumatic events most associated with subsequent development of Post Traumatic Stress Disorder (PTSD) in Canada (Van Ameringen, Mancini, Patterson, \& Boyle, 2008) and the United States (Amstadter, McCart, \& Ruggiero, 2007; Kessler, 2000). Moreover, violent crimes generate more severe and chronic symptoms of PTSD (Breslau et al., 1998; Norris \& Kaniasty, 1994; Stein, Walker, Hazen, \& Forde, 1997).

The interpersonal nature of being exposed to a violent crime appears to contribute to greater immediate psychological distress compared to survivors of natural disasters or motor vehicle accidents (MVA) victims (Ozer, Best, Lipsey, \& Weiss, 2008, Hetzel-Riggin \& Roby, 2012). Peritraumatic distress (PDI) refers to emotional and physical stress responses that occur during or immediately after the traumatic event (Thomas, Saumier, \& Brunet, 2012). It primarily involves the perception that one's life in endangered as well as the presence of negative emotions such as fear, horror, helplessness, shame and anger. Peritraumatic distress reactions are very prevalent among victims of intentionally caused traumas (e.g., physical violence, robbery victims, sexual assaults). Elevated PDI is more frequent among victims of assaults than those of

traffic accidents (Frans, Rimmö, Åberg, \& Fredrikson, 2005). In a recent study among undergraduate students who were victims of interpersonal trauma, the majority of participants endorsed symptoms of PTSD criterion A2 in the DSM-VI-TR (e.g., presence of either intense fear, horror or helplessness) (Valdez \& Lilly, 2014). Furthermore, life-threatening events such as violent crimes might put the victims at greater risk for experiencing dissociative reactions (Johansen, Wahl, Eilertsen, Hanestad, \& Weisaeth, 2006). Dissociative symptoms that occur during or immediately after the traumatic event and that are likely bring modifications or gaps in conscious awareness (Bryant, 2007) are referred to as peritraumatic dissociation (PD). 
Dissociative reactions prevent proper encoding of the event when processing trauma memories (Bryant, 2007; Friedman, Keane, \& Resick, 2007) and could explain why traumatic memories become fragmented (Ehlers \& Clark, 2000). They include symptoms such as derealisation (e.g., distorted perception of reality), depersonalization (e.g., feeling disconnected from one's own body), dissociative amnesia or experiences of emotional numbing or detachment, and reduced awareness of one's surroundings. Recently, PD experiences were found to be more prevalent in victims of interpersonal violence compared to participants who had experienced the loss of a loved one or a natural disaster (Hetzel-Riggin \& Roby, 2012).

In terms of peritraumatic reactions and their association with PTSD risk, a longitudinal study investigating PTSD among victims of violent crimes (VVC) found that presenting intense peritraumatic emotions (e.g., horror) predicted PTSD 6 months post-crime (Brewin, Andrews, \& Rose, 2000b). Perception of life threat (included in the PDI construct) also predicted PTSD among VVC in comparison to accident victims (Ozer et al., 2008). PDI following various types of trauma among randomly selected civilians was found to contribute more to PTSD diagnosis than sex and ethnicity (Frans et al.,2005). As for PD, it has recently been found to predict PTSD severity as well as its chronicity in various clinical and non-clinical samples (Cardeña and Carlson, 2011).While a relationship between PD and PTSD has been established in many studies, Armour \& al. (2014) recently highlighted that conflicting data exist. For instance, substantial effect sizes $(\approx 0.40)$ between PD and posttraumatic symptomatology were reported in a meta analysis (Lensvelt-Mulders et al., 2008), whilst a systematic review including prospective studies on VVC did not show that PD was an independent predictor of PTSD (Van der Velden \& Wittmann, 2008). Methodological differences across studies in the type or timing of the measures or in the type of sample investigated may explain some of the inconsistencies observed in the literature (Carlson, Dalenberg, \& McDade-Montez, 2012). In sum, meta-analyses (Brewin, 
Andrews, \& Valentine, 2000a; Ozer et al., 2008) emphasize that peritraumatic psychological processes such as the subjective perception of life threat show the strongest risk for PTSD, in comparison to more static factors like age, personality traits or prior exposure.

Further, gender could possibly play a role in these associations. In fact, women have a two-fold higher risk of develop PTSD compared to men (Tolin \& Foa, 2006; Van Ameringen et al., 2008). It has been hypothesized that sex differences in the perception of life threat and in the processing of strong emotional memories may contribute to women's greater vulnerability for PTSD (Olff, Langeland, Draijer, \& Gersons, 2007). However, literature on gender differences in peritraumatic reactions among victims of violent crime is scarce. Gender differences in PDI were observed in a few investigations including other trauma populations. In a study involving earthquake survivors, psychological distress induced by exposure to trauma cues (PTSD criteria B4; DSM-5) was more frequently endorsed by men, whereas a persistent negative emotional state and dissociative reactions (criteria D4 and B3, respectively) were mostly reported by women (Carmassi et al., 2014). Another study demonstrated that women exposed to interpersonal violence were overrepresented in the endorsement of criterion A2 (Valdez et. al., 2014). This could imply higher PDI levels for women, although not measured directly. Mostly, this literature has mainly focused on gender differences in persistent distress. In terms of peritraumatic dissociation, high levels were found for both sexes in a study among Palestinians from the Gaza strip, and it did not predict PTSD differently in men and women (Punamäki, Komproe, Qouta, Elmasri, \& de Jong, 2005). Contradictory evidence also exists in the MVA victims' literature. One study found that women who experienced PD were at greater risk of developing PTSD, although men and women reported similarly low frequencies of PD symptoms (Fullerton, et al., 2001). PD was further found to account for gender differences in PTSD development within the same population (Irish et al., 2011). 
There is currently little research on gender differences in the associations between peritraumatic variables and PTSD in a sample of VVC. To our knowledge, only one study explored some of our variables of interest within the same population. Indeed, Christiansen \& Hansen (2015) found that female victims of a bank robbery exhibited more negative peritraumatic emotions, dissociation and negative post-traumatic cognitions. Additionally, these variables appeared to mediate PTSD severity among women. In sum, the few results emerging from studies in MVA victims have not been replicated among VVC.

The first aim of the present study is to investigate whether peritraumatic reactions predict PTSD. The second objective is to examine whether gender moderates the relationship between PD, PDI and PTSD development in VVC. Considering potential gender differences in peritraumatic distress and dissociation as well as women's greater vulnerability for PTSD, we predicted that female VVC would present with significantly greater levels of PD and PDI compared to men. It was also expected that these would be better predictors of PTSD in female VVC compared to men. Finally, in contrast to prior research, which has mostly employed selfreport instruments to measure PTSD, the current study used a semi-structured interview. We were interested in examining whether assessing PTSD with the use of a semi-structured interview altered PD and PDI's role in establishing the diagnosis, as a function of gender.

\section{Methods}

\section{Participants}

The overall design of this study is prospective. Participants were recruited for a broader longitudinal study investigating risk factors for ASD and PTSD, and the efficacy of a brief cognitive-behavioural treatment involving a significant other in the treatment of ASD and the prevention of PTSD development. The sample comprised 214 victims of violent crimes (125 
women) aged 18-75 years $\left(\mathrm{M}_{\mathrm{age}}=39.4\right.$ years, $\left.\mathrm{SD}=13.75\right)$. Victims were recruited between 2009 and 2014 via collaborations with the Montreal Crime Assistance Centers (CAC) in Canada. Participants were included if they met the following eligibility criteria: a) exposure to a violent crime within 30 days prior to the reference from the $\mathrm{CAC}$; b) at least 18 years of age c) good mastery of French or English, d) not suffering from a bipolar disorder, past or present psychotic episode, organic brain disorder, traumatic brain injury and/or active suicidal ideations.

\section{Procedure}

Each participant was initially met by a CAC counsellor, as part of the usual care provided to victims in Montreal. The counsellor would then inform all victims of this research project up to 28 days post-crime (e.g., the timeframe to screen for ASD). Individuals willing to participate contacted the research coordinator by telephone and received a standardised and detailed description of the study. Following verbal consent, a short interview (20 min) was conducted to assess eligibility and to specify the event's circumstances.

Eligible participants who initially verbally consented to the study underwent semi-structured clinical interviews at the Trauma Studies Center of the Research Center of Institut universitaire en santé mentale de Montréal on two occasions. Trained doctoral level research assistants assessed the presence of an ASD diagnosis and self-report measures of peritraumatic distress and dissociation, as well as other risk factors for PTSD were administered (T0), following the interviews. In order to meet the main objectives of the larger study, participants were then assigned into one of three cohorts (1) brief CBT intervention with the involvement of a significant other, (2) brief CBT intervention involving the victim only and (3) usual care.

Participants were reassessed 2 months (T1) following crime exposure $\left(\mathrm{M}_{\text {days }}=73\right)$ in order to establish PTSD diagnosis. Doctoral students trained in the various instruments performed 
assessments at both time points face-to-face. Participants received a $20 \$$ compensation following each completed assessment.

\section{Measurement}

\section{Socio-demographic variables}

Data on sex, age in years, marital and employment status, and education levels was collected.

\section{Measures of symptomatology}

PTSD was measured categorically to establish the presence or absence of a diagnosis as well as continuously in terms of the number of symptoms. Thus, measures from two instruments were obtained. The PTSD module of the Structured Clinical Interview for DSM-IV (SCIDI;(First \& Gibbon, 2004)) was administered by a qualified interviewer to evaluate the presence of past and/or ongoing PTSD among participants and to assess for comorbid disorders. Partial PTSD was diagnosed when one criteria was not met (e.g., missing symptoms on the dissociative criteria). A kappa of 0.86 was obtained for inter-rater reliability for the PTSD diagnosis in this study. The Modified PTSD Symptom Scale (MPSS; (Resick, Falsetti, Resnick, \& Kilpatrick, 1991) is a self-administered 17-item questionnaire that assesses PTSD symptoms represented on two subscales, severity and frequency. Overall scores vary from 0-119 with a cut off at 50 for PTSD diagnosis. The instrument has excellent internal consistency (alphas of .97 for the total score) and good convergent validity with the PTSD module on the SCID (Guay, Marchand, Iucci, \& Martin, 2002).

The Peritraumatic Dissociative Experiences Questionnaire (PDEQ; Marmar et al., 1994) is a 10-item self-report questionnaire that assesses peritraumatic dissociative experiences, including derealisation, depersonalization, dissociative amnesia, out of body experiences and altered time perception or body image (van der Velden \& Wittmann, 2008). A cut-off score of 15 
and higher represents survivors who reported highly dissociative experiences (Civilotti et al., 2015). Psychometrics properties for the validated French version (Martin \& Marchand, 2003) are good, with an internal consistency of 0.85 and a test-retest reliability score of 0.88 .

The Peritraumatic Distress Inventory is a 13-item self-report instrument rated on a fourpoint Likert scale (0; not at all, 4; extremely true; Brunet et al., 2001) that measures PD on 2 subscales: perception of life threat (6 items) and negative emotions ( 7 items). The internal consistency (0.83) and test-retest reliability (0.79) for the French version are good (Jehel, Brunet, Paterniti, \& Guelfi, 2005). A cut-off score of 14 and higher can be used to identify highly distressed individuals (Guardia, et al., 2013).

Exposure to past potentially traumatic events was measured with the Life Events Checklist (Blake et al., 1998), a 17-item self-report questionnaire that assesses exposure to several types of traumatic events using a Likert scale (it happened to me, I witnessed it, I have heard of it, n/a). Psychometric properties are adequate with fair reliability (stable over a 1-week period) and strong convergence with measures of PTSD symptoms (Gray, Litz, Hsu, \& Lombardo, 2004).

\section{Data Analyses}

Analyses were based on 111 participants (68 women) for whom complete data was available for PTSD diagnosis and severity. According to t-tests and chi-squares on the variables of interests, completers and dropouts did not differ significantly. One exception with age was found $(\mathrm{t}(160)=-2.24, \mathrm{p}=0.026)$ with completers being slightly older $\left(\mathrm{M}_{\text {age: }} 41\right.$ vs 35 years old $)$. The sample was distributed normally on main variables and covariates; therefore no data transformation was required. Dummy variables were created for PTSD diagnosis (e.g., full and partial combined compared to no diagnosis), thus allowing for subclinical PTSD to be considered in the analyses. 
The selection of potential covariates was based on a review of significant PTSD risk factors or on potentially significant risk factors (Pearson's $r>0.25$ ) identified in this sample. These were age, education, the number of potential past traumatic events and the type of violent crime. Cohort type was also included as a covariate, since data were collected at the 2-month post-trauma assessment (T1), after a portion of the participants had received brief CBT (with or without a significant other).

The main analyses involved multiple hierarchical regressions to test whether PD and PDI predicted PTSD differently according to gender. PTSD was entered as a continuous variable measured with scores on the MPSS. Relevant covariates were entered simultaneously in Block 1, and Block 2 included the main effects (PD and PDI). Interaction terms (2-ways) were created with centered variables and entered in Block 3 (gender*dissociation, gender*distress). In order to determine if treatment is moderating the association between PD/PDI and PTSD, two more interactions terms were necessary and added in Block 4 (PD*treatment, PDI*treatment). Treatment variable was dichotomized (participants who received CBT and usual care). Moreover, since we have previously shown that an acute stress diagnosis predicted later PTSD (Guay, Gravel-Crevier, Boyer \& Marchand, in press), a second regression model was conducted including ASD as measured by the number of symptoms met on the Acute Stress Disorder Interview (ASDI (Bryant, Harvey, Dang, Sackville, \& Basten, 1998)). This additional covariate was added in Block 1 Statistical significance was set at $p<0.05$.

The same objectives were then tested for categorical variables. Chi-square tests were performed with PTSD, measured categorically with the SCID, as the outcome variable. Predictors were gender, PDI, and PD. Regarding peritraumatic variables; most participants $(>80 \%)$ obtained scores well above the cut-offs suggested in the literature (please report to Table 1 for means and SD). Therefore, statistical cut-offs as used in many studies were chosen 
(Menting, Van Lier, Koot, Pardini \&Loeber, 2016). These identified the most dissociative and distressed half of the sample. For the purposes of this paper, individuals above the $50^{\text {th }}$ percentile were considered as experiencing very high levels of dissociative and distress symptoms.

Participants below the $50^{\text {th }}$ percentile experienced moderate levels of peritraumatic reactions.

\section{Results}

Table 1 describes the sample characteristics and the observed differences between women and men. Women experienced significantly more PDI, including a perception of life, threat and negative emotions than men, but not significantly more PD. Other t-tests were performed and no significant gender differences were observed among covariates, neither for the presence of a PTSD diagnosis (full or partial) nor for symptoms (see Table 1).

Pearson correlations performed to identify potential covariates showed significant but modest associations between education, previous potentially traumatic events and PTSD (measured by the MPSS) among women. In men, a strong and positive association was observed between age, current traumatic event, and PTSD. These variables were included in further regressions. Significant positive correlations were observed between main independent variables (e.g., PDI and PD) and the intensity of PTSD symptoms. Comprehensive results are shown in Table 2.

Full regression models and standardized Betas are presented in Table 3. Significant main

effects emerged for both peritraumatic variables. In general, as the intensity of PDI and PD increased, a higher number of PTSD symptoms were observed. Analyses did not show any significant interaction effect with gender, suggesting that no gender differences were present in the relation between PD/PDI and PTSD. Treatment (CBT) was found significant for PDI among 
VVC. The usual care group was associated to higher PDI levels; however, this association is mitigated for the CBT group $(B=0.47, p=0.0003)$. Similar results were obtained when controlling for ASD; however, peritraumatic dissociation did not increase PTSD symptoms. Please refer to Table 4.

Globally, chi-square tests revealed a significant gender difference in the occurrence of PTSD (as diagnosed with the SCID) with a higher percentage of women presenting a full PTSD diagnosis compared to men. Figure 1 demonstrates the proportion of women and men who experienced moderate to high peritraumatic distress when diagnosed with PTSD. Higher levels of PDI were associated with a PTSD diagnosis for both men and women with no significant gender differences. These results need to be interpreted with caution as the group of men with high PDI but no PTSD diagnosis had an expected count of less than 5. Similar results were obtained for peritraumatic dissociation with no significant gender differences (see Figure 2).

\section{Discussion}

Findings from this study confirm that acute stress reactions, specifically peritraumatic distress and dissociation, predict endorsement of significantly more PTSD symptoms two months post-trauma in both male and female survivors of a violent crime. Women were more likely to be diagnosed with PTSD compared to men, though this was most evident using the semi-structured interview rather than self-report questionnaires, as typically used in prior research. In line with previous studies, ASD also predicted later development of PTSD in VVC (Brewin, Andrews, \& Rose, 2003; Elklit \& Brink, 2004). However, the extent to which peritraumatic variables predicted PTSD was not moderated by gender, failing to support the main hypothesis. This will be developed further. 


\section{Victims of violent crimes: highly distressed and prone to dissociation}

Results revealed significant peritraumatic reactions in this sample of VVC. In fact, only a very small proportion of victims did not experience significant PD and PDI (7.4\% and 13.6\%, respectively). Moreover, in this sample, PDI was an important aspect in how PTSD was later experienced, with almost all the victims recalling negative emotions during the traumatic event supporting the elimination of the A2 criterion in the DSM-5. Likewise, violent crimes seem to induce high levels of both peritraumatic reactions simultaneously. This is consistent with findings in sexually assaulted women (Griffin, Resick, \& Mechanic, 1997) where it was hypothesized that dissociation may be a coping strategy to deal with extreme anxiety as experienced in lifethreatening situations. Our results support this hypothesis and also demonstrate a similar pattern in men.

\section{Peritraumatic responses are associated with PTSD among victims of violent crimes}

The fact that greater peritraumatic reactions were associated with a higher number of PTSD symptoms in the current sample is consistent with a growing body of evidence (Dalenberg \& Carlson, 2012; Ozer et al., 2008; Griffin et al., 1997). Previous studies reported that the presence of negative peritraumatic emotions (e.g., fear, horror and helplessness) and PD were predictive of PTSD onset in VVC (Brewin, Andrews Rose, 2000b; Elklit \& Brink, 2004). A more recent investigation on MVA survivors showed that PD predicted PTSD 6 months later but was not a significant predictor of ASD (Irish et al., 2011). The current study confirms the importance of addressing peritraumatic reactions in VVC. It also contributes to the body of research on gender differences by highlighting the fact that differences may not lie in peritraumatic reactions. Other possible mechanisms could be at play. 
Additionally, currently used self-report questionnaires (e.g., PDEQ and the PDI) may not be adapted for VVC. In a study conducted by the authors of the PDEQ, as many as $75 \%$ of rescue workers who responded to an earthquake fell under the cut-off (Marmar, 1996). Future research should consider revising or adapting the questionnaires for VVC. This could include explaining dissociative reactions to participants in order to ensure that the right construct is measured and that the obtained score is more faithful to the peritraumatic reactions experienced. Based on clinical data, dissociative experiences are often difficult to understand for victims. To our knowledge, only one study adapted the PDEQ for their population of interest (female rape victims) using items from the PDEQ in a semi-structured clinical interview and replacing two items with dissociative experiences more common among rape victims. Thus, a relatively normal distribution of PD was obtained, reducing possible biases arising from such elevated responses (Griffin et al., 1997).

\section{Similar findings obtained for men and women exposed to severe interpersonal traumas}

No gender differences were observed in the extent to which peritraumatic variables predicted PTSD diagnosis. This was not expected given differences previously noted in the literature on MVA victims, in which women who experienced more dissociative symptoms were more vulnerable to PTSD than men (Bryant \& Harvey, 2003; Fullerton et al., 2001; Irish et al., 2011). Several factors could explain these null findings.

One explanation may lie in the nature of the traumatic event. Women were found to be more vulnerable to PTSD development compared to men in situations involving accidents or disasters but less so following violent crimes, among which gender differences were the smallest (Ditlevsen \& Elklit, 2012). Indeed, very few studies found significant gender differences among VVCs. Few investigations have suggested that the nature of the trauma event might influence the relationship between peritraumatic variables and PTSD. For instance, in a study on men and 
women exposed to either an explosion incident or a violent crime, PD was a significant risk factor for PTSD only among women who survived the explosion (Christiansen \& Elklit, 2008), whereas PD significantly predicted PTSD in both male and female VVC. Further, when exposed to interpersonal trauma in the context of military violence, no gender differences were found in the prediction of PTSD from PD (Punamäki et al., 2005). PD experiences could be similar in extremely severe events. Interpersonal traumas could be viewed as more distressing, since they may impede significantly more on the victim's initial schemas of the world as a safe and predictable environment, in both men and women.

The absence of gender differences could also be due to the low variability or a floor effect of the independent variables. Perhaps for violent crimes, severe levels of PD and PDI mask possible differences between men and women. Indeed, elevated levels of peritraumatic variables were found in both male and female VVC in this sample, and these variables predicted PTSD development to a similar extent for both genders.

In their study on MVA victims, Bryant \& Harvey (2003) demonstrated that ASD was a more accurate predictor for PTSD in women because of stronger peritraumatic dissociative experiences. They proposed that these gender differences could be due to: a) underreporting of symptoms by men, b) neurobiological factors, supported by findings that women respond more effectively to certain medication (sertraline) in the treatment of PTSD or, c) a greater number of female passengers vs. drivers reducing their perception of control over the accident. Yet, the male participants in this sample reported a high and similar number of peritraumatic symptoms as women, suggesting that underreporting of symptoms is an unlikely explanation for the lack of gender differences in our study.

Another way to interpret the similar results observed among men and women in the current study is by considering the psychological impact of the event on participants. It is 
possible that VVC suffer more intensely than survivors from other traumatic events, since surprisingly, only $4 \%$ of participants were below the established cut-off for PD (15). Small numbers of low PD and PDI were observed for men as well as women.

\section{Strengths, limitations, and research implications}

The current study has several strengths. This is a prospective longitudinal investigation with a follow-up at two months post-crime assessing PTSD diagnosis. This research design allowed for the examination of the continuing effects of peritraumatic reactions on PTSD in a sample of VVC, with similar numbers of men and women. This sample is likely representative of crime victims as Crime Assistance Centers (CAC) are well established in Montreal and crime survivors will regularly contact this organisation on their own initiative. Moreover, we can assume that victims using avoidance strategies as a coping method will be less present in this sample even if struggling with intense PD and PDI levels. Additionally, data on peritraumatic variables were collected soon after exposure to the crime, reducing the probability of inaccurate self-reports that could contaminate the results (Rosen, 2004). However, assessment in very close proximity with the actual peritraumatic period was not possible in all cases. Finally, analyses controlled for many known PTSD risk factors including ASD.

Certain methodological limitations must be mentioned. First, the sample size prevented us from conducting logistic regressions. Cell sizes from the cross tabs analyses might not have been large enough to reveal statistically significant gender differences. As such, results regarding the presence versus absence of PTSD need to be interpreted with caution. Nonetheless, our sample size and attrition rates are consistent with those of other studies on VVC (Elklit \& Brink, 2004). Undeniably, participants in this research were exposed to extremely severe and distressing events and the violence of these crimes could have led to inaccurate self-reporting, whereas subjective appraisals of life threat might have been amplified if they were to be compared with 
objective physiological measures. We believe future research might benefit from measuring physiological and neurobiological factors following exposure (Inslicht et al., 2013; Lanius et al., 2010), in emergency units for instance, where VVC may be treated soon after the event. This could also ensure to reduce retrospective assessments in the self-reported peritraumatic experiences.

\section{Clinical Implications and future directions}

Peritraumatic distress and dissociation are significant predictors of PTSD in VVC. However, women were not more vulnerable to PTSD as a result of PD or PDI compared to men, highlighting the pertinence for clinicians to screen both men and women for PTSD after a violent crime. Results also shed light on functional aspects of PD, which has often been viewed as a coping or learned response that obstructs the recognition of danger (Bremner, 1999). This mechanism does not seem to be involved in perception of danger for $\mathrm{VVC}$, considering the high levels of PDI. PDI even remained predictive of the number of PTSD symptoms after ASD was controlled for. Perhaps negative emotions experienced in the context of interpersonal violence need to be specifically addressed when treating ASD, as they seem to have longer lasting effects on victims' mental health. Furthermore, it had been previously noted that men and women tend to vary in how they cognitively process and assess danger in their primary appraisal of the event (Olff et al., 2007). In this sample, recognition of danger was similar for both sexes, but examining specific peritraumatic cognitions could reveal differences and thereby shed light on mechanisms at play with PD, since it couldn't predict PTSD when ASD was controlled for. It is also good practice to advise clinicians to continue to target the perceived threat to one's life and negative emotions, since this peritraumatic reaction is highly prevalent and may lead to the development of more chronic PTSD among VVC. Finally, future studies should examine gender dimensions in addition to reported gender. Gender is generally understood as a socially 
prescribed and experienced dimension of femaleness and maleness in a society, exemplified by gender roles (Johnson, Greaves, \& Repta, 2009). The relations between adherence to feminine and masculine characteristics and the expression of peritraumatic distress and dissociation should be explored to increase our knowledge on sex and gender in the context of a violent crime. 


\section{References}

Armour, C., Elklit, A., Lauterbach, D., \& Elhai, J. D. (2014). The DSM-5 dissociative-PTSD subtype: Can levels of depression, anxiety, hostility, and sleeping difficulties differentiate between dissociative-PTSD and PTSD in rape and sexual assault victims? Journal of anxiety disorders, 28(4), 418-426.

Amstadter, A. B., McCart, M. R., \& Ruggiero, K. J. (2007). Psychosocial interventions for adults with crime-related PTSD. Professional Psychology: Research and Practice, 38(6), 640.

Blake, D. D., Weathers, F. W., Nagy, L. M., Kaloupek, D. G., Charney, D. S., \& Keane, T. M. (1998). Clinicianadministered PTSD scale for DSM-IV. Boston: National Center for Posttraumatic Stress Disorder.

Bremner, J. D. (1999). Acute and chronic responses to psychological trauma: where do we go from here? American Journal of Psychiatry.

Breslau, N., Kessler, R. C., Chilcoat, H. D., Schultz, L. R., Davis, G. C., \& Andreski, P. (1998). Trauma and Posttraumatic Stress Disorder in the Community, The 1996 Detroit Area Survey of Trauma. Archives of General Psychiatry, 55(7), 626-632.

Brewin, Andrews, B., \& Valentine, J. D. (2000a). Meta-analysis of risk factors for posttraumatic stress disorder in trauma-exposed adults. Journal of Consulting and Clinical Psychology, 68(5), 748-766.

Brewin, C. R., Andrews, B., \& Rose, S. (2000b). Fear, helplessness, and horror in posttraumatic stress disorder: Investigating DSM-IV Criterion A2 in victims of violent crime. Journal of Traumatic Stress, 13(3), 499-509.

Brewin, C. R., Andrews, B., \& Rose, S. (2003). Diagnostic overlap between acute stress disorder and PTSD in victims of violent crime. American Journal of Psychiatry, 160(4), 783-785.

Brunet, A., Weiss, D. S., Metzler, T. J., Best, S. R., Neylan, T. C., Rogers, C., et al. (2001). The Peritraumatic Distress Inventory: a proposed measure of PTSD criterion A2. American Journal of Psychiatry, 158(9), 14801485.

Bryant, R. A. (2007). Does dissociation further our understanding of PTSD? Journal of Anxiety Disorders, 21(2), $183-191$.

Bryant, R. A., \& Harvey, A. G. (2003). Gender differences in the relationship between acute stress disorder and posttraumatic stress disorder following motor vehicle accidents. Australian and New Zealand Journal of Psychiatry, 37(2), 226-229.

Bryant, R. A., Harvey, A. G., Dang, S. T., Sackville, T., \& Basten, C. (1998). Treatment of acute stress disorder: a 
comparison of cognitive-behavioral therapy and supportive counseling. Journal of Consulting and Clinical Psychology, 66(5), 862.

Cardeña, E., \& Carlson, E. (2011). Acute stress disorder revisited. Annual Review of Clinical Psychology, 7, 245267.

Carlson, E. B., Dalenberg, C., \& McDade-Montez, E. (2012). Dissociation in posttraumatic stress disorder part I: Definitions and review of research. Psychological Trauma-Theory Research Practice and Policy, 4(5), 479.

Carmassi, C., Akiskal, H. S., Bessonov, D., Massimetti, G., Calderani, E., Stratta, P., et al. (2014). Journal of Affective Disorders, 160(C), 55-61.

Christiansen, D. M., \& Elklit, A. (2008). Risk factors predict post-traumatic stress disorder differently in men and women. Psychological Review, 7(1), 24.

Christiansen, D. M., \& Hansen, M. (2015). Accounting for sex differences in PTSD: A multi-variable mediation model. European Journal of Psychotraumatology, 6.

Civilotti, C., Castelli, L., Binaschi, L., Cussino, M., Tesio, V., Di Fini, G., et al. (2015). Dissociative symptomatology in cancer patients. Frontiers in Psychology, 6.

Dalenberg, C., \& Carlson, E. B. (2012). Dissociation in posttraumatic stress disorder part II: How theoretical models fit the empirical evidence and recommendations for modifying the diagnostic criteria for PTSD. Psychological Trauma-Theory Research Practice and Policy, 4(6), 551.

Ditlevsen, D. N., \& Elklit, A. (2012). Gender, trauma type, and PTSD prevalence: a re-analysis of 18 nordic convenience samples. Annals of General Psychiatry, 11(1),1.

Ehlers, A., \& Clark, D. M. (2000). A cognitive model of posttraumatic stress disorder. Behaviour Research and Therapy, 38(4), 319-345.

Elklit, A., \& Brink, O. (2004). Acute Stress Disorder as a Predictor of Post-Traumatic Stress Disorder in Physical Assault Victims. Journal of Interpersonal Violence, 19(6), 709-726.

First, M. B., \& Gibbon, M. (2004). The Structured Clinical Interview for DSM-IV Axis I Disorders (SCID-I), and the Structured Clinical Interview for DSM-IV Axis II Disorders (SCID-II).

Frans, Ö., Rimmö, P. A., Åberg, L., \& Fredrikson, M. (2005). Trauma exposure and post-traumatic stress disorder in the general population. Acta Psychiatrica Scandinavica, 111(4), 291-299.

Friedman, M. J., Keane, T. M., \& Resick, P. A. (Eds.). (2007). Handbook of PTSD: Science and practice. Guilford 
Press.

Fullerton, C. S., Ursano, R. J., Epstein, R. S., Crowley, B., Vance, K., Kao, T.-C., ... Baum, A. (2001). Gender Differences in Posttraumatic Stress Disorder After Motor Vehicle Accidents. American Journal of Psychiatry, $158(9), 1486-1491$.

Gray, M. J., Litz, B. T., Hsu, J. L., \& Lombardo, T. W. (2004). Psychometric properties of the life events checklist. Assessment, 11(4), 330-341.

Griffin, M. G., Resick, P. A., \& Mechanic, M. B. (1997). Objective assessment of peritraumatic dissociation: Psychophysiological indicators. American Journal of Psychiatry, 154(8), 1081-1088.

Guardia, D., Brunet, A., Duhamel, A., Ducrocq, F., Demarty, A.-L., \& Vaiva, G. (2013). Prediction of TraumaRelated Disorders: A Proposed Cutoff Score for the Peritraumatic Distress Inventory. The Primary Care Companion for CNS Disorders, 15(1).

Guay, S., Gravel-Crevier, M., Boyer, R., \& Marchand, A. (November 2014). ASD diagnosis, clusters and symptoms as predictors of PTSD in women and men victims of violent crimes. Poster presented at the annual congress of the International Society for Traumatic Stress Studies (ISTSS), Miami, USA.

Guay, S., Marchand, A., Iucci, S., \& Martin, A. (2002). Validation de la version Québécoise de l'Échelle Modifiée des Symptômes du Trouble de Stress Post-Traumatique auprès d'un échantillon clinique. Revue Québécoise De Psychologie.

Hetzel-Riggin, M. D., \& Roby, R. P. (2013). Trauma type and gender effects on PTSD, general distress, and peritraumatic dissociation. Journal of Loss and Trauma, 18(1), 41-53.

Inslicht, S. S., Metzler, T. J., Garcia, N. M., Pineles, S. L., Milad, M. R., Orr, S. P., et al. (2013). Sex differences in fear conditioning in posttraumatic stress disorder. Journal of Psychiatric Research, 47(1), 64-71.

Irish, L. A., Fischer, B., Fallon, W., Spoonster, E., Sledjeski, E. M., \& Delahanty, D. L. (2011). Gender differences in PTSD symptoms: an exploration of peritraumatic mechanisms. Journal of Anxiety Disorders, 25(2), 209216.

Johansen, V. A., Wahl, A. K., Eilertsen, D. E., Hanestad, B. R., \& Weisaeth, L. (2006). Acute psychological reactions in assault victims of non-domestic violence: Peritraumatic dissociation, post-traumatic stress disorder, anxiety and depression. Nordic journal of psychiatry, 60(6), 452-462.

Jehel, L., Brunet, A., Paterniti, S., \& Guelfi, J. D. (2005). Validation of the Peritraumatic Distress Inventory's French 
translation. Canadian Journal of Psychiatry, 50(1), 67-71.

Johnson, J.L., L. Greaves, and R. Repta, (2009). Better science with sex and gender: Facilitating the use of a sex and gender-based analysis in health research. International Journal for Equity in Health Soc Work,. 8(14).

Kessler, R. C. (2000). Posttraumatic stress disorder: the burden to the individual and to society. Journal of Clinical Psychiatry. 61(Suppl 5), 4-12.

Lanius, R. A., Vermetten, E., Loewenstein, R. J., Brand, B., Schmahl, C., Bremner, J. D., \& Spiegel, D. (2010). Emotion modulation in PTSD: Clinical and neurobiological evidence for a dissociative subtype. American Journal of Psychiatry, 167(6), 640-647.

Lensvelt-Mulders, G., van Der Hart, O., van Ochten, J. M., van Son, M. J., Steele, K., \& Breeman, L. (2008). Relations among peritraumatic dissociation and posttraumatic stress: A meta-analysis. Clinical Psychology Review, 28(7), 1138-1151.

Marmar, C. R. (1996). Characteristics of emergency services personnel related to peritraumatic dissociation during critical incident exposure. American Journal of Psychiatry, 153(7), 94.

Marmar, C. R., Weiss, D. S., Schlenger, W. E., Fairbank, J. A., Jordan, B. K., Kulka, R. A., \& Hough, R. L. (1994). Peritraumatic dissociation and posttraumatic stress in male Vietnam theater veterans. American Journal of Psychiatry, 151(6), 902-907.

Martin, A., \& Marchand, A. (2003). Prediction of Posttraumatic Stress Disorder: Peritraumatic Dissociation, Negative Emotions and Physical Anxiety Among French-Speaking University Students. Journal of Trauma \& Dissociation, 4(2), 49-63.

Menting, B., Van Lier, P. A., Koot, H. M., Pardini, D., \& Loeber, R. (2016). Cognitive impulsivity and the development of delinquency from late childhood to early adulthood: Moderating effects of parenting behavior and peer relationships. Development and psychopathology, 28(01), 167-183.

Norris, F. H., \& Kaniasty, K. (1994). Psychological distress following criminal victimization in the general population: Cross-sectional, longitudinal, and prospective analyses. Journal of Consulting and Clinical Psychology, 62(1), 111.

Olff, M., Langeland, W., Draijer, N., \& Gersons, B. P. R. (2007). Gender differences in posttraumatic stress disorder. Psychological Bulletin, 133(2), 183-204.

Ozer, E. J., Best, S. R., Lipsey, T. L., \& Weiss, D. S. (2008). Predictors of posttraumatic stress disorder and 
symptoms in adults: a meta-analysis. (p. 3). Presented at the Annual Meeting of the International Society for Traumatic Stress Studies, 14th, Nov, 1998, Washington, DC, USA

Punamäki, R.-L., Komproe, I. H., Qouta, S., Elmasri, M., \& de Jong, J. T. V. M. (2005). The Role of Peritraumatic Dissociation and Gender in the Association Between Trauma and Mental Health in a Palestinian Community Sample. American Journal of Psychiatry, 162(3), 545-551.

Resick, P. A., Falsetti, S. A., Resnick, H. S., \& Kilpatrick, D. G. (1991). The modified PTSD symptom scale-self report. 1991,72 .

Rosen, G. (2004). Posttraumatic stress disorder: Issues and controversies. John Wiley \& Sons.

Stein, M. B., Walker, J. R., Hazen, A. L., \& Forde, D. R. (1997). Full and partial posttraumatic stress disorder: findings from a community survey. American Journal of Psychiatry, 154(8), 1114-1119.

Thomas, É., Saumier, D., \& Brunet, A. (2012). Peritraumatic distress and the course of posttraumatic stress disorder symptoms: a meta-analysis. Canadian Journal of Psychiatry, 57(2), 122-129.

Tolin, D. F., \& Foa, E. B. (2006). Sex differences in trauma and posttraumatic stress disorder: a quantitative review of 25 years of research. Psychological bulletin, 132(6), 959.

Valdez, C. E., \& Lilly, M. M. (2014). Biological sex, gender role, and Criterion A2: Rethinking the "gender" gap in PTSD. Psychological Trauma-Theory Research Practice and Policy, 6(1), 34.

Van Ameringen, M., Mancini, C., Patterson, B., \& Boyle, M. H. (2008). Post-Traumatic Stress Disorder in Canada. CNS Neuroscience \& Therapeutics, 14(3), 171-181.

van der Velden, P. G., \& Wittmann, L. (2008). The independent predictive value of peritraumatic dissociation for PTSD symptomatology after type I trauma: A systematic review of prospective studies. Clinical Psychology Review, 28(6), 1009-1020. 
Table 1. Sample Characteristics and Comparisons between Genders

\begin{tabular}{|c|c|c|}
\hline & Men $(n=43)$ & Women $(n=68)$ \\
\hline Age (years \pm SD) & $43.5(2.45)$ & $39.8(1.55)$ \\
\hline Marital Status n (\%) & & \\
\hline Single & 58.1 & 49.3 \\
\hline Married/Living with someone & 30.2 & 32.8 \\
\hline Separated/Divorced/Widowed & 11.6 & 17.9 \\
\hline Education n (\%) & & \\
\hline High School diploma or less & 34.9 & 42.9 \\
\hline Post-Secondary & 65.1 & 57.4 \\
\hline Employment Status (\%) & & \\
\hline Employed & 69.8 & 67.6 \\
\hline Previous PTSD (\%) & 14 & 16.2 \\
\hline Current traumatic Event n (\%) & & \\
\hline Physical Assault & 81.4 & 48.6 \\
\hline Sexual Assault/domestic violence & 2.3 & 27.9 \\
\hline $\begin{array}{l}\text { Other violent crime (e.g., threats, } \\
\text { witness) }\end{array}$ & 16.3 & 23.5 \\
\hline Peritraumatic Dissociation (SD) & $27.9(1.4)$ & $29.68(1.12)$ \\
\hline Peritraumatic Distress (SD) & $23.96(1.74)^{* *}$ & $31.13(1.28)$ \\
\hline Perceived life threat & $12.33^{* *}$ & 15.54 \\
\hline Negative emotions & $11.63^{* *}$ & 15.59 \\
\hline PTSD Diagnosis (\%) & $15(35.7 \%)$ & $23(35.9 \%)$ \\
\hline PTSD subclinical level (\%) & $11(26.2 \%)$ & $14(21.9 \%)$ \\
\hline PTSD symptoms (SD) & $46.44(5.24)$ & $47.35(3.32)$ \\
\hline
\end{tabular}

$* \mathrm{p}=0.05, * * \mathrm{p}=0.001$ 
Table 2. Bivariate Associations between PTSD as measured by the Modified PTSD Symptom Scale and Demographic variables, Peritraumatic Reactions, Potential Covariates (Pearson's r)

\begin{tabular}{lcc}
\hline \multicolumn{1}{c}{ PTSD } & Men (43) & Women (68) \\
\hline Age & $.446^{* *}$ & $\mathrm{~ns}$ \\
Education & $\mathrm{ns}$ & $0.327^{* *}$ \\
Marital Status & $\mathrm{ns}$ & $\mathrm{ns}$ \\
$\begin{array}{lc}\text { Previous Potential } \\
\text { Traumatic Events }\end{array}$ & $\mathrm{ns}$ & $0.288^{*}$ \\
$\begin{array}{l}\text { Perceived Social } \\
\text { Support }\end{array}$ & $\mathrm{ns}$ & $\mathrm{ns}$ \\
$\begin{array}{l}\text { Past PTSD Diagnosis } \\
\text { Peritraumatic }\end{array}$ & $\mathrm{ns}$ & $\mathrm{ns}$ \\
$\begin{array}{l}\text { Dissociation } \\
\text { Peritraumatic Distress }\end{array}$ & $0.452^{* *}$ & $0.409^{* *}$ \\
Current Traumatic & & \\
Event (type of crime) & $0.523^{* *}$ & $\mathrm{~ns}$ \\
\hline$*$ p $=0.05, * * \mathrm{p}=0.001$ & $-0.453^{* *}$ & \\
\hline
\end{tabular}


Table 3. Summary of Hierarchical Regression Model Predicting PTSD (\# symptoms) from Peritraumatic Dissociation and Distress in in Men and Women

\begin{tabular}{|l|c|c|c|}
\hline Block 1 & $\boldsymbol{\beta}$ & $\boldsymbol{t}$ & $\boldsymbol{p}$ \\
\hline Gender & 0.069 & 0.690 & 0.491 \\
\hline Treatment & -0.010 & -0.107 & 0.915 \\
\hline Age & 0.127 & 1.337 & 0.184 \\
\hline Education & $\mathbf{0 . 2 4 8}$ & $\mathbf{2 . 6 4 7}$ & $\mathbf{0 . 0 0 9}$ \\
\hline Current event type: sexual assault & -0.014 & -0.134 & 0.893 \\
\hline Current event type: other crime & -0.141 & -1.424 & 0.157 \\
\hline Previous potential traumatic events & 0.151 & 1.565 & 0.121 \\
\hline \multicolumn{4}{|c|}{$\mathrm{F}_{\text {model }}(7,110)=2.124, p=.047$} \\
$\mathrm{R}^{2}{ }_{\text {model }}=0.126, \mathrm{R}^{2}{ }_{\text {adj }}=0.067$ \\
\hline Block 2 & $\boldsymbol{\beta}$ & $\boldsymbol{t}$ \\
\hline Peritraumatic Distress & $\mathbf{0 . 3 7 0}$ & $\mathbf{3 . 4 7 2}$ & $\mathbf{0 . 0 0 1}$ \\
\hline Peritraumatic Dissociation & $\mathbf{0 . 2 1 7}$ & $\mathbf{2 . 2 5 0}$ & $\mathbf{0 . 0 2 7}$ \\
\hline \multicolumn{4}{|c|}{$\mathrm{R}_{\text {model }}^{2}=0.341, \mathrm{R}^{2}{ }_{\text {adj }}=0.282$} \\
\hline \\
\hline
\end{tabular}

$\mathrm{N}=111$, Covariates accounted for $12.6 \%$ of the variance 
Table 4. Hierarchical Regression Predicting PTSD (\# symptoms) from Peritraumatic Dissociation and Distress in in Men and Women when controlling for ASD

\begin{tabular}{|c|c|c|c|}
\hline Block 1 & $\boldsymbol{\beta}$ & $t$ & $p$ \\
\hline Gender & -0.036 & -0.411 & 0.682 \\
\hline Treatment & 0.154 & 1.826 & 0.071 \\
\hline Age & 0.122 & 1.512 & 0.134 \\
\hline Education & 0.156 & 1.929 & 0.056 \\
\hline Current event type: sexual assault & 0.027 & 0.305 & 0.761 \\
\hline Current event type: other crime & -0.129 & -1.530 & 0.129 \\
\hline Previous potential traumatic events & 0.019 & 1.228 & 0.820 \\
\hline Acute Stress Disorder & 0.553 & 6.325 & 0.000 \\
\hline \multicolumn{4}{|c|}{$\begin{array}{c}\mathrm{F}_{\text {model }}(8,110)=7.563, p=.001 \\
\mathrm{R}_{\text {model }}^{2}=0.372, \mathrm{R}_{\text {adj }}^{2}=0.323\end{array}$} \\
\hline Block 2 & $\boldsymbol{\beta}$ & $t$ & $p$ \\
\hline Peritraumatic Distress & 0.260 & 2.550 & 0.012 \\
\hline Peritraumatic Dissociation & 0.111 & 1.197 & 0.234 \\
\hline \multicolumn{4}{|c|}{$\begin{array}{c}\mathrm{F}_{\text {model }}(10,110)=6.094, p<.002 \\
\mathrm{R}_{\text {model }}^{2}=0.441, \mathrm{R}_{\text {adj }}^{2}=0.385\end{array}$} \\
\hline Block 3 & $\boldsymbol{\beta}$ & $\underline{t}$ & $p$ \\
\hline gender* peritraumatic distress & -0.042 & -0.441 & 0.660 \\
\hline gender * peritraumatic dissociation & -0.019 & -0.196 & 0.845 \\
\hline \multicolumn{4}{|c|}{$\begin{array}{c}\mathrm{F}_{\text {model }}(12,110)=6.504, p=.781 \\
\mathrm{R}_{\text {model }}^{2}=0.443, \mathrm{R}_{\text {adj }}^{2}=0.375\end{array}$} \\
\hline
\end{tabular}


Figure 1

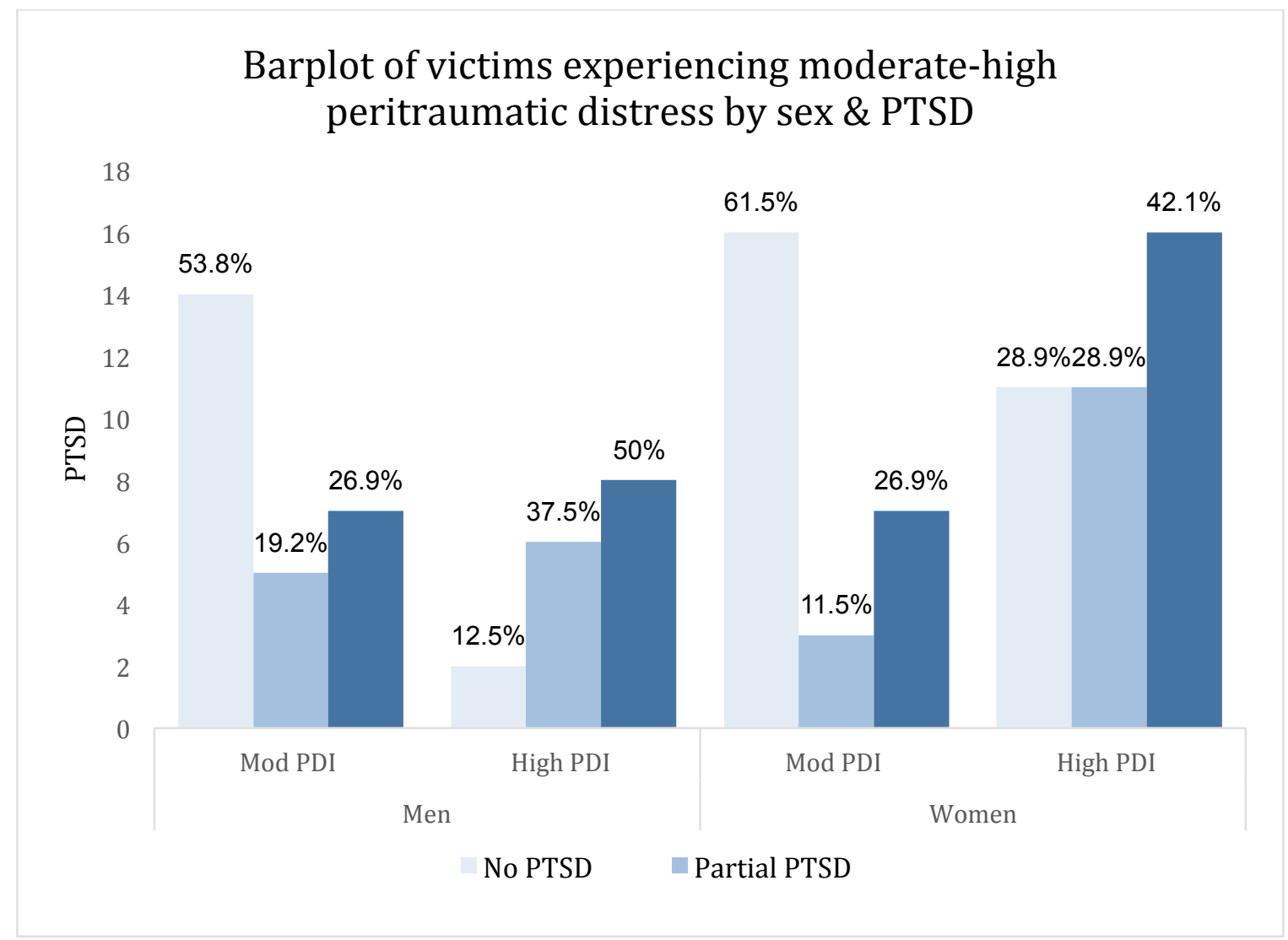

Mod PDI: scores below 29 on the PDI were considered as moderate

High PDI: scores of 29 and above on the PDI were considered as high 
Figure 2

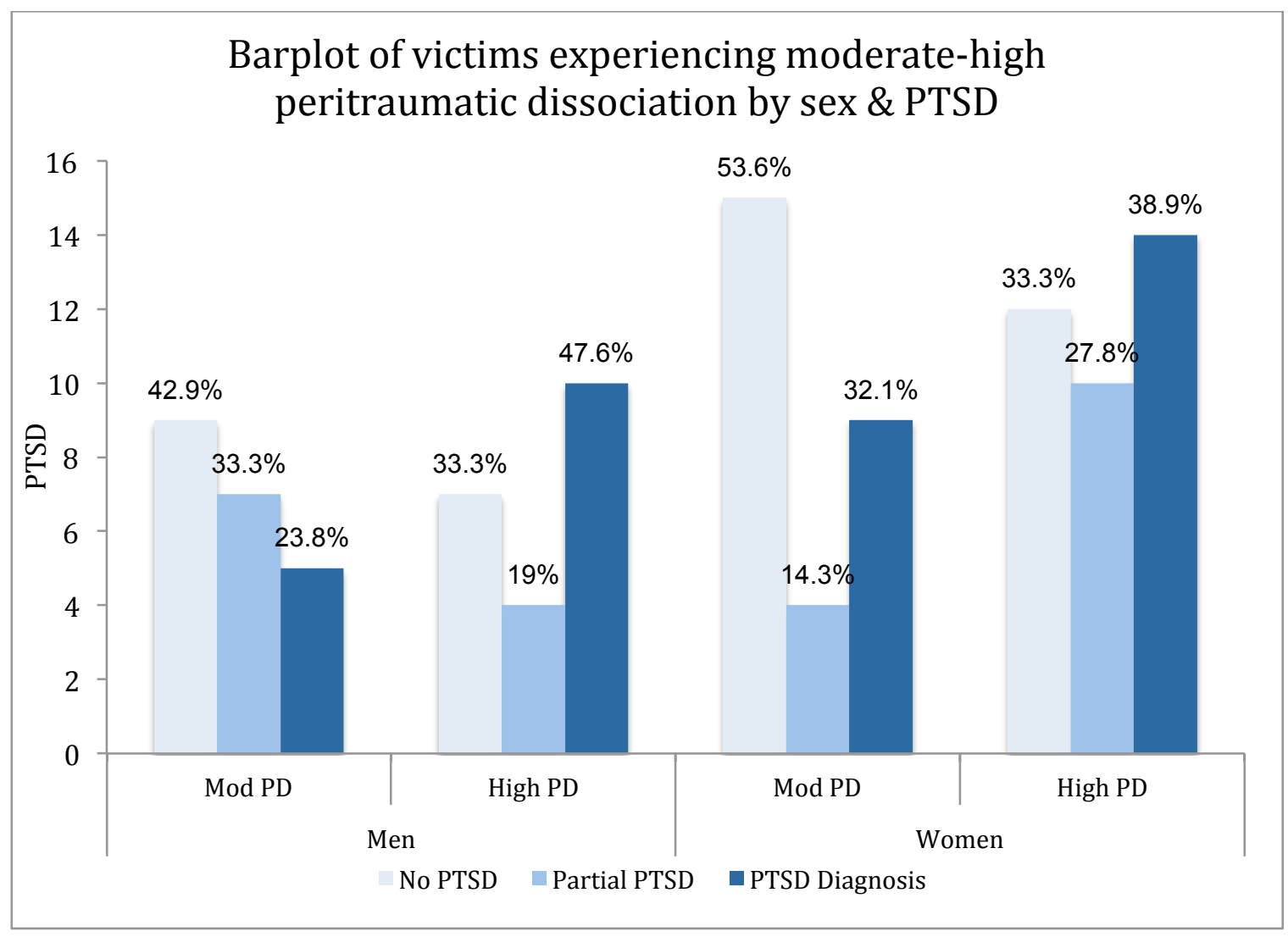

Mod PD: scores below 29 on the PDEQ were considered as moderate

High PD: scores of 29 and above on the PDEQ were considered as high 